\title{
SOME WEAK TYPE ESTIMATES FOR MAXIMAL SINGULAR INTEGRALS
}

\author{
SHUICHI SATO
}

\begin{abstract}
We consider some maximal singular integral operators having variable kernels on $\mathbb{R}^{n}$ with doubling measures and prove $L^{p}$ and weak type estimates for them under certain conditions. Also, certain weighted weak type estimates are shown for maximal singular integrals with $A_{1}$ weights of Muckenhoupt for the Lebesgue measure.
\end{abstract}

Mathematics subject classification (2020): Primary 42B20, 42B25.

Keywords and phrases: Maximal singular integrals, weighted weak type estimates.

\section{REFERENCES}

[1] A. Benedek, A. P. Calderón and R. Panzone, Convolution operators on Banach space valued functions, Proc. Nat. Acad. Sci. U.S.A. 48 (1962), 356-365.

[2] A. P. Calderón, M. Weiss and A. Zygmund, On the existence of singular integrals, Proc. Sympos. Pure Math., vol. 10, Amer. Math. Soc., Providence, R.I., 1967, pp. 56-73.

[3] A. P. Calderón And A. Zygmund, A note on singular integrals, Studia Math. 65 (1979), 77-87.

[4] M. Christ AND J. L. RUBIO DE FRAnCIA, Weak type $(1,1)$ bounds for rough operators, II, Invent. Math. vol. 93, 1988, 225-237.

[5] R. R. Coifman And Y. Meyer, Au delà des opérateurs pseudo-différentiels, Astérisque no. 57, Soc. Math. France, 1978.

[6] R. R. Coifman And G. WeIss, Analyse Harmonique Non-Commutative sur Certains Espaces Homogenes, Lecture Notes in Math. 242, Springer-Verlag, Berlin and New York, 1971.

[7] J. DuoAndikoetXeA AND J. L. Rubio DE FRANCIA, Maximal and singular integral operators via Fourier transform estimates, Invent. Math. 84 (1986), 541-561.

[8] D. FAN AND S. SATO, Weak type $(1,1)$ estimates for Marcinkiewicz integrals with rough kernels, Tohoku Math. J. 53 (2001), 265-284.

[9] D. FAN AND S. SATO, Weighted weak type $(1,1)$ estimates for singular integrals and LittlewoodPaley functions, Studia Math. 163 (2004), 119-136.

[10] G. B. Folland, Real Analysis Modern Techniques and Their Applications, 1984, A WileyInterscience Publication.

[11] J. Garcia-CuerVa And J. L. Rubio De Francia, Weighted Norm Inequalities and Related Topics, 1985, North-Holland.

[12] D. J. H. GARLing, Inequalities A Journey into Linear Analysis, Cambridge University Press, 2007.

[13] S. Hofmann, Weighted weak-type $(1,1)$ inequalities for rough operators, Proc. Amer. Math. Soc. vol. 107, 1989, 423-435.

[14] L. HöRMANDER, Estimates for translation invariant operators in $L^{p}$ spaces, Acta Math. 104 (1960), 93-139.

[15] J.-L. Journé, Calderón-Zygmund Operators, Pseudo-Differential Operators and the Cauchy Integral of Calderón, Lecture Notes in Math. vol. 994, 1983, Springer-Verlag.

[16] D. S. Kurtz AND R. L. WheEden, Results on weighted norm inequalities for multipliers, Trans. Amer. Math. Soc. 255 (1979), 343-362.

[17] N. Rivière, Singular integrals and multiplier operators, Ark. Mat. 9 (1971), 243-278.

[18] J. L. Rubio de Francia, F. J. Ruiz and J. L. Torrea, Calderón-Zygmund theory for operatorvalued kernels, Adv. in Math. 62 (1986), 7-48. 
[19] W. Rudin, Real and Complex Analysis, third edition, 1987, McGraw-Hill.

[20] S. SAто, Weak type $(1,1)$ estimates for parabolic singular integrals, Proc. Edinb. Math. Soc. 54 (2011), 221-247.

[21] S. SATo, Estimates for singular integrals on homogeneous groups, J. Math. Anal. Appl. 400 (2013), 311-330.

[22] S. SATO, Weighted weak type $(1,1)$ estimates for singular integrals with non-isotropic homogeneity, Ark. Mat. 54 (2016), 157-180.

[23] A. SEeger, Singular integral operators with rough convolution kernels, J. Amer. Math. Soc. vol. 9, 1996, 95-105.

[24] E. M. Stein, Singular Integrals and Differentiability Properties of Functions, 1970, Princeton Univ. Press.

[25] T. TAO, The weak-type $(1,1)$ of L $\log L$ homogeneous convolution operator, Indiana Univ. Math. J. vol. 48, 1999, 1547-1584.

[26] A. VARGAS, Weighted weak type $(1,1)$ bounds for rough operators, J. London Math. Soc. (2) vol. 54, 1996, 297-310. 